\title{
The phylogeny of extant starfish (Asteroidea: Echinodermata) including Xyloplax, based on comparative transcriptomics
}

\author{
Gregorio V. Linchangco Jr. ${ }^{\mathrm{a}, *}$, David W. Foltz ${ }^{\mathrm{b}}$, Rob Reid ${ }^{\mathrm{a}}$, John Williams ${ }^{\mathrm{a}}$, Conor Nodzak ${ }^{\mathrm{a}}$, \\ Alexander M. Kerr ${ }^{\mathrm{c}}$, Allison K. Miller ${ }^{\mathrm{c}}$, Rebecca Hunter ${ }^{\mathrm{d}}$, Nerida G. Wilson ${ }^{\mathrm{e}, \mathrm{f}}$, William J. Nielsen ${ }^{g}$, \\ Christopher L. Mah ${ }^{\mathrm{h}}$, Greg W. Rouse ${ }^{\mathrm{e}}$, Gregory A. Wray ${ }^{\mathrm{g}}$, Daniel A. Janies ${ }^{\mathrm{a}, *}$ \\ a Department of Bioinformatics and Genomics, University of North Carolina at Charlotte, Charlotte, NC, USA \\ b Department of Biological Sciences, Louisiana State University, Baton Rouge, LA, USA \\ ${ }^{\mathrm{c}}$ Marine Laboratory, University of Guam, Mangilao, GU, USA \\ d Department of Biology, Abilene Christian University, Abilene, TX, USA \\ e Scripps Institution of Oceanography, University of California San Diego, La Jolla, CA, USA \\ ${ }^{\mathrm{f}}$ Western Australian Museum, Locked Bag 49, Welshpool DC, Western Australia 6986, Australia \\ ${ }^{8}$ Department of Biology and Center for Genomic and Computational Biology, Duke University, Durham, NC, USA \\ ${ }^{\text {h }}$ Department of Invertebrate Zoology, Smithsonian Institution, Washington, District of Columbia, USA
}

\section{A R T I C L E I N F O}

\section{Keywords:}

Transcriptomics

Phylogeny

Asteroidea

Crown-group

Echinodermata

\begin{abstract}
A B S T R A C T
Multi-locus phylogenetic studies of echinoderms based on Sanger and RNA-seq technologies and the fossil record have provided evidence for the Asterozoa-Echinozoa hypothesis. This hypothesis posits a sister relationship between asterozoan classes (Asteroidea and Ophiuroidea) and a similar relationship between echinozoan classes (Echinoidea and Holothuroidea). Despite this consensus around Asterozoa-Echinozoa, phylogenetic relationships within the class Asteroidea (sea stars or starfish) have been controversial for over a century. Open questions include relationships within asteroids and the status of the enigmatic taxon Xyloplax. Xyloplax is thought by some to represent a newly discovered sixth class of echinoderms - and by others to be an asteroid. To address these questions, we applied a novel workflow to a large RNA-seq dataset that encompassed a broad taxonomic and genomic sample. This study included 15 species sampled from all extant orders and 13 families, plus four ophiuroid species as an outgroup. To expand the taxonomic coverage, the study also incorporated five previously published transcriptomes and one previously published expressed sequence tags (EST) dataset. We developed and applied methods that used a range of alignment parameters with increasing permissiveness in terms of gap characters present within an alignment. This procedure facilitated the selection of phylogenomic data subsets from large amounts of transcriptome data. The results included 19 nested data subsets that ranged from 37 to 4,281 loci. Tree searches on all data subsets reconstructed Xyloplax as a velatid asteroid rather than a new class. This result implies that asteroid morphology remains labile well beyond the establishment of the body plan of the group. In the phylogenetic tree with the highest average asteroid nodal support several monophyletic groups were recovered. In this tree, Forcipulatida and Velatida are monophyletic and form a clade that includes Brisingida as sister to Forcipulatida. Xyloplax is consistently recovered as sister to Pteraster. Paxillosida and Spinulosida are each monophyletic, with Notomyotida as sister to the Paxillosida. Valvatida is recovered as paraphyletic. The results from other data subsets are largely consistent with these results. Our results support the hypothesis that the earliest divergence event among extant asteroids separated Velatida and Forcipulatacea from Valvatacea and Spinulosida.
\end{abstract}

\section{Introduction}

Echinodermata are a unique animal phylum in that most species have bilaterally symmetrical larvae followed by pentaradial adult stages. However, echinoderm larvae and adults display great diversity in form and life history (McEdward and Janies, 1997). Extant echinoderms include two clades, class Crinoidea (sea lilies) and superclass Eleutherozoa [classes Asteroidea (starfish or sea stars), Ophiuroidea (brittlestars), Echinoidea (sea urchins), and Holothuroidea (sea cucumbers)]. Historically echinoderm workers have considered two major

\footnotetext{
* Corresponding authors at: Department of Bioinformatics and Genomics, 9201 University City Blvd, Charlotte, NC 28223, USA.

E-mail addresses: glinchan@uncc.edu (G.V. Linchangco), djanies@uncc.edu (D.A. Janies).
} 
competing hypotheses for the relationship of Asteroidea to other classes within Eleutherozoa (reviewed in Smith (1984) and Janies et al. (2011)). The first hypothesis is the cryptosyringid hypothesis, which posits that the classes Echinoidea, Holothuroidea, and Ophiuroidea form a clade known as Cryptosyringida, sister to the Asteroidea. The Cryptosyringid hypothesis is primarily based on a putative synapomorphy of an enclosed radial water vessel (Smith, 1984). An alternative hypothesis for the evolutionary relationships of extant Eleutherozoa is the Asterozoa-Echinozoa hypothesis. Asterozoa includes the stellate forms asteroids and ophiuroids. The monophyly of the Asterozoa is based on the putative synapomorphy of the adult body plan including stellate form and the construction of the mouth frame and ambulacral ossicles (Mooi and David, 2000). The Echinozoa includes holothuroids and echinoids. The monophyly of the Echinozoa is supported by the shared globose shape (Smith 1984). Janies (2001) used modest amounts of Sanger sequencing and morphology to show that there is more support for Asterozoa-Echinozoa than Cyrptosyringida across an alignment parameter space. Later, Janies et al. (2011) used combined Sanger sequencing data and morphology to show that Asterozoa and Echinozoa are methods-dependent when alignment and optimality criteria are varied. Recent transcriptomic studies with limited taxonomic and locus sampling have supported Asterozoa-Echinozoa (Cannon et al., 2014; O'Hara et al., 2014; Telford et al., 2014; Reich et al., 2015; Simakov et al., 2015) and were reviewed by Peterson and Eernisse (2016). These studies also strongly supported a monophyletic Asteroidea, consistent with prior morphological analyses including fossils (Blake et al., 2000; Shackleton, 2005) and molecular studies (Janies, 2001; Janies et al., 2011).

All previous transcriptomic studies lack the enigmatic Xyloplax. In the 1980s, this small disc-shaped echinoderm was discovered on sunken wood in the deep sea off the coasts of the Bahamas and New Zealand (Baker et al., 1986). Xyloplax was initially described as having a circular water vascular system (Baker et al., 1986; Janies and McEdward, 1994a, 1994b) but later was re-described as having a derived pentaradial system with ambulacra splayed out to the periphery of the body (Janies and Mooi, 1998; Mooi et al., 1998; Janies et al., 2011). The small size and odd morphology of Xyloplax fueled the already fierce debate over echinoderm phylogeny (Smith, 1988; Pearse and Pearse, 1994; Janies and Mooi, 1998). A table of hypotheses for the placement of Xyloplax and their proponents is presented in Table 1. Some workers erected a new sixth class of extant echinoderms containing only Xyloplax (Baker et al., 1986). Subsequently, Rowe et al. (1988) proposed a working hypothesis that united Xyloplax and valvatid asteroids. In doing so, these workers expressed a desire to keep Xyloplax as a class distinct from the asteroids - which was self-contradictory. In contrast, several researchers have argued that Xyloplax is an aberrant asteroid and that erecting a new class is not warranted (Smith, 1988; Janies and Mooi, 1998; Janies, 2001; Janies et al., 2011).

Another enduring quandary in asteroid phylogeny has concerned the earliest cladogenetic events giving rise to living asteroid lineages. This discussion was historically framed as the question of whether the

Table 1

Various hypotheses for the placement of Xyloplax.

\begin{tabular}{ll}
\hline Hypothesis & Authors \\
\hline New echinoderm class & Baker et al. (1986) \\
& Rowe et al. (1988) \\
Infraclass within the Asteroidea & Mah (2006) \\
Asteroidea (Velatida) & Smith (1988) \\
Asteroidea (Caymanostellidae) & Belyaev (1990) \\
Asteroidea (Forcipulatida) & Janies and Mooi (1998) \\
& Janies (2001) \\
Asteroid (Velatida) & Janies et al. (2011) \\
& Janies (2013) \\
& This paper \\
\hline
\end{tabular}

order Paxillosida (or one of its member families) diverged early or late during asteroid evolution. Evidence has been presented for (Mortensen, 1922, 1923; Fell, 1962a, 1962b, 1963; Gale, 1987; Lafay et al., 1995; Wada et al., 1996; Gale, 2013) and against (MacBride, 1921, 1923a, 1923b; Madsen, 1966; Blake, 1972, 1987, 1988; Janies et al., 2011; Mah and Blake, 2012; Blake and Mah, 2014) an early divergence of Paxillosida among asteroid lineages. Recent morphological and molecular-based hypotheses of phylogenetic relationships amongst traditional asteroid orders are summarized in Fig. 1.

The controversy illustrated in Fig. 1 underscores the need for a wellsupported molecular phylogeny for asteroids, to permit the resolution of early divergence of asteroid orders as well as allow the placement of problematic and morphologically unusual taxa. Here, we used the recent demonstration, via molecular analyses of echinoderms (Janies, 2001; Cannon et al., 2014; O'Hara et al., 2014; Telford et al., 2014; Reich et al., 2015; Simakov et al., 2015) and our own broader analyses, that ophiuroids (brittlestars) are the sister group to asteroids and the outgroup of choice. However, recent transcriptomic analyses sampled asteroids poorly (Cannon et al., 2014; O'Hara et al., 2014; Telford et al., 2014; Reich et al., 2015; Simakov et al., 2015). Specifically, O’Hara et al. (2014) and Telford et al. (2014) each sampled two asteroids, Simakov et al. (2015) sampled one asteroid and Cannon et al. (2014) sampled four asteroids. Reich et al. (2015) sampled 11 asteroids, but only four families that represented four orders were studied. To better understand the phylogeny of extant asteroids and the placement of Xyloplax, we employed RNA-seq data to assemble thousands of orthologous loci for 15 species sampled from all extant asteroid orders and 13 families, plus four ophiuroid species as an outgroup (Table 2). To expand the taxonomic coverage, the study incorporated five previously published transcriptomes and one previously published expressed sequence tags (EST) dataset. Photographs of taxa of interest are shown in Fig. 2.

\section{Materials and methods}

\subsection{Sampling}

In terms of gene and taxon sampling, our sequence datasets are the largest assembled to date for asteroid phylogenetics (15 asteroid species from all orders and 13 families). We sampled families within orders to span the largest taxonomic divergences ascertained from earlier work. RNA-Seq data was obtained from four ophiuroid taxa for use as outgroups (Ophiocoma wendtii, Ophiothrix spiculata, Astrophyton muricatum, and Ophioderma brevispinum). We added data from published asteroid transcriptome sequences for the species Asterias amurensis, Asterias forbesi, Asterias rubens, Marthasterias glacialis and Leptasterias sp. (Reich et al., 2015). cDNA data for Patiria pectinifera was obtained from http:// www.ncbi.nlm.nih.gov/biosample/LIBEST_019589, 45-h embryonic tissue. For quality control, one of the asteroid species served as a technical replicate (i.e. Peribolaster 1 and Peribolaster 2, two pieces of the same specimen used in separate library preparation and Illumina runs).

\subsection{RNA extraction, sequencing and data pre-processing}

We extracted RNA from muscle tissue samples (adult tube feet, pinnules or body wall) using a Qiagen miRNEasy kit. An Agilent Bioanalyzer 2100 ver. 2.6 was used for quality control prior to library preparation. Samples were then submitted to the Duke Center for Genomic and Computational Biology for library preparation with an Illumina TruSeq RNA kit, followed by RNA-Seq sequencing on an Illumina Hiseq 2000 platform (100 BP, paired end). Reads for each of the samples were filtered by quality score (cutoff threshold > Q20) by FASTXFILTER and filtered for adapters by way of cutadapt, both components of the FASTX-Toolkit (http://hannonlab.cshl.edu/fastx_ toolkit/). De novo assembly of contigs was then performed using 


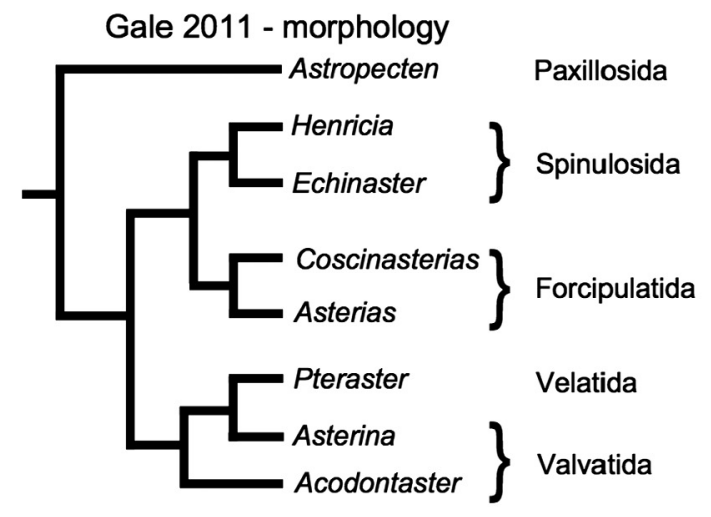

Janies et al. 2011 - molecules

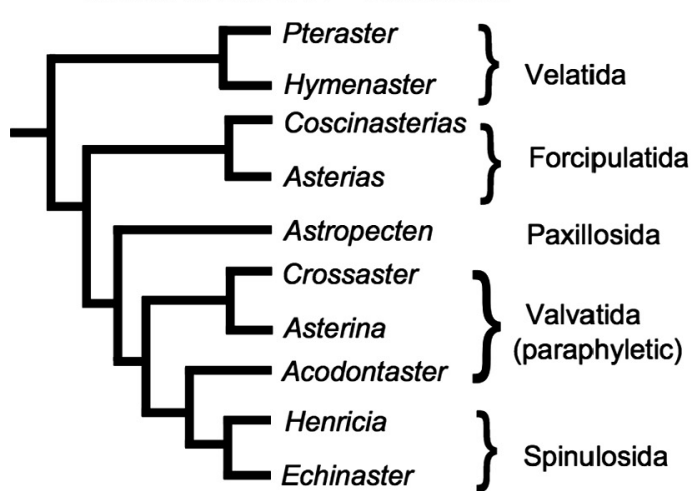

Mah and Blake 2012 combined molecules \& morphology

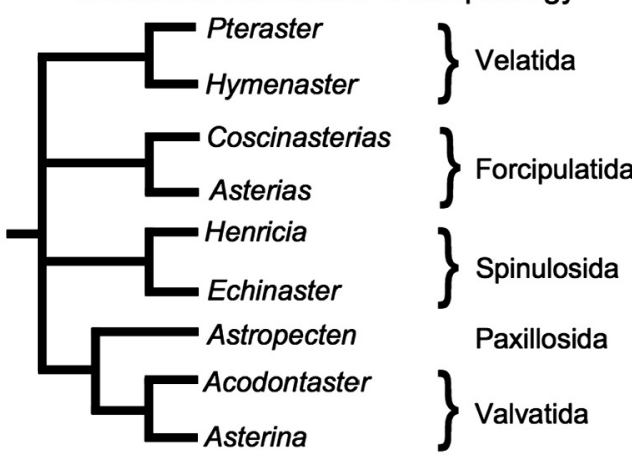

Knott and Wray 2000 - molecules

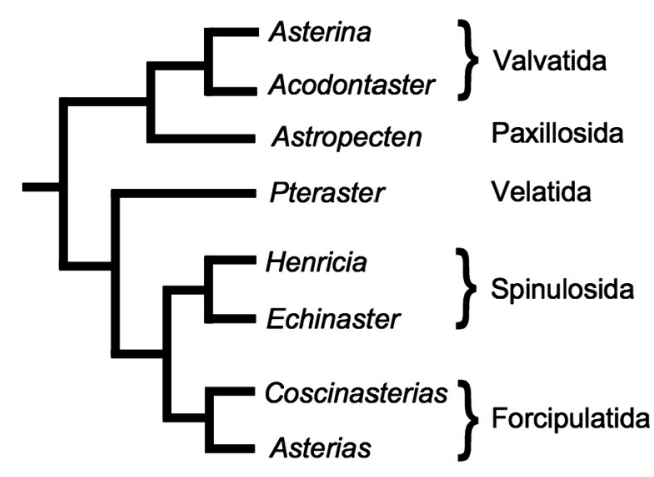

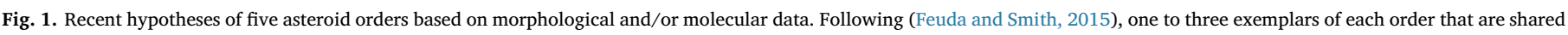

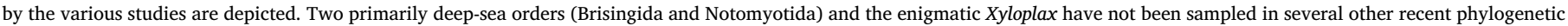

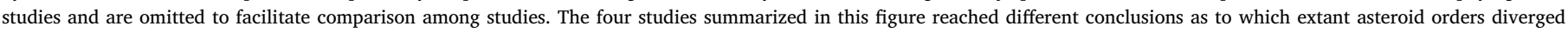

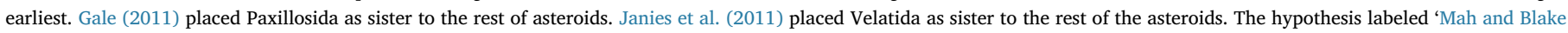

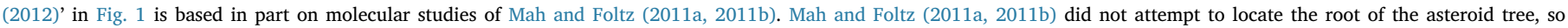

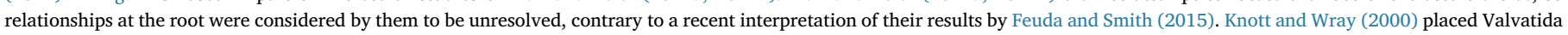
and Paxillosida as sister to the rest of the asteroids.

Trinity (Haas et al., 2013) on a high memory compute cluster using $500 \mathrm{~GB}$ of RAM and 24 CPUs. The resultant contigs for each sample was subsequently translated into amino acid space using Transdecoder (http://transdecoder.github.io/) and the PFAM-B protein family database (Finn et al., 2010), with a lower cutoff of 100 amino acids.

\subsection{Taxonomic conventions}

Taxonomic conventions for the sampled ingroup species followed recent nomenclatural changes reflected in http://www.marinespecies. org/asteroidea. Noteworthy changes included the change of Porania antarctica to Glabraster antarctica, following revisions to the Poraniidae by Mah and Foltz (2014). Sequences obtained from the Xyloplax in this study suggest that it may be a new species, which will be described elsewhere (Rouse, pers. comm.). To facilitate comparison to recent studies of asteroid relationships (Fig. 1) we describe our results using the conventional asteroid orders. This study is focused on high-level relationships within asteroids and, for simplicity, our selected vouchers are referred to by their currently assigned genus in our discussion, with our species identifications provided in our tables and figures.

\subsection{Ortholog identification, alignment construction and phylogenetic analysis with paralogs}

Each putative amino acid sequence was compared via a BLASTP search across all other contigs to discover orthologous clusters (orthoclusters) using OrthoMCL (Li, 2003). Following orthocluster discovery, a taxonomic filter of having at least eight asteroids and one ophiuroid species was applied to all orthoclusters to obtain the initial dataset. Additional sequences from six species were then added to the RNA-Seq derived dataset via a BLASTP search on the longest asteroid sequence in the orthologous cluster versus sequence data from the species Asterias amurensis, A. forbesi, A. rubens, Marthasterias glacialis, Leptasterias sp. from Reich et al. (2015) and published cDNA data for Patiria pectinifera from http://www.ncbi.nlm.nih.gov/biosample/ LIBEST_019589, 45-h embryonic tissue. Overall, the process of ortholog identification produced 5,868 orthoclusters for the initial dataset.

Multiple sequence alignment was then performed on each of the 5,868 orthoclusters using MAFFT 7.0130 (Katoh, 2002). To increase the quality of the aligned orthoclusters prior to tree construction, we used a two-step process including the program TrimAL (Capella-Gutiérrez et al., 2009) and an in-house Python script we call "BOXER" (https:// github.com/supramap/boxer) (Fig. 3). First, TrimAL removed difficult to align sequences via a command line interface employing alignment statistics. BOXER then selected from aligned orthoclusters produced by TrimAL, preferring those aligned orthoclusters with the user-defined number of unique taxa and allowed percentage of gaps in the alignment. The difficult to align sequences were identified via the two parameters from TrimAL as described in the manual (http://trimal. cgenomics.org/_media/tutorial.pdf): (1) "residue overlap" which is a percentage of residues in an aligned orthocluster column that must be occupied with other residues (not gaps or missing data), and (2) "sequence overlap" which is a percentage of positions with observed residues (not gaps or missing data) that a row in an aligned orthocluster must have in order to be kept in the alignment. If a sequence did not fulfill both user thresholds for these parameters, it was removed from the orthocluster alignment. This process was performed for 36 different 
Table 2

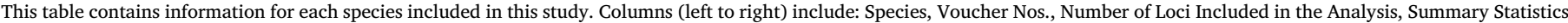
for Transcriptome Pre-Preprocessing of Illumina Hi-Seq Read Counts Before (Raw) And After Quality Filtering and Adapter Removal, Bioproject Accession Nos.

\begin{tabular}{|c|c|c|c|c|c|c|}
\hline Species & Voucher no. ${ }^{\mathrm{e}}$ & No. of loci & No. of raw reads & No. of reads removed & $\%$ Reads removed & Bioproject accession No. ${ }^{\mathrm{d}}$ \\
\hline Asteropsis carinifera & KSORC 000276 & 1847 & $55,750,932$ & $9,694,411$ & 17.39 & PRJNA 299419 \\
\hline Astropecten duplicatus & SIO-BIC E6745 & 1790 & $58,536,934$ & $10,879,260$ & 18.59 & PRJNA 299417 \\
\hline Astrophyton muricatum ${ }^{\mathrm{a}}$ & SIO-BIC E6741 & 1285 & $52,762,224$ & $9,218,837$ & 17.47 & PRJNA 299886 \\
\hline Cheiraster sp. & SIO-BIC E4758 & 55 & $30,190,658$ & $4,898,857$ & 16.23 & PRJNA 299420 \\
\hline Echinaster spinulosus & $-^{c}$ & 836 & $58,483,838$ & $3,074,717$ & 5.26 & PRJNA 300370 \\
\hline Glabraster antarctica & SIO-BIC E5520 & 1517 & $54,906,620$ & $9,703,154$ & 17.67 & PRJNA 299418 \\
\hline Henricia leviuscula & SIO-BIC E5597 & 1980 & $61,618,432$ & $11,331,247$ & 18.39 & PRJNA 299415 \\
\hline Labidiaster annulatus & SIO-BIC E4756 & 2531 & $88,022,282$ & $3,838,195$ & 4.36 & PRJNA 299411 \\
\hline Luidia clathrata & SIO-BIC E6744 & 1526 & $60,248,000$ & $10,583,107$ & 17.57 & PRJNA 299414 \\
\hline Odinella nutrix & SIO-BIC E4241 & 38 & $40,650,604$ & $7,334,900$ & 18.04 & PRJNA 299463 \\
\hline Ophiocoma wendtii ${ }^{\mathrm{a}}$ & $-^{c}$ & 189 & $39,062,818$ & $2,601,837$ & 6.66 & PRJNA 299897 \\
\hline Ophioderma brevispina ${ }^{\mathrm{a}}$ & SIO-BIC E6743 & 974 & $55,865,966$ & $8,969,129$ & 16.05 & PRJNA 299887 \\
\hline Ophiothrix spiculata & $-c$ & 364 & $47,255,758$ & $2,588,148$ & 5.48 & PRJNA 299898 \\
\hline Patiria pectinifera ${ }^{\mathrm{b}}$ & $-{ }^{\mathrm{b}}$ & 616 & - & - & - & - \\
\hline Peribolaster folliculatus 1 & SIO-BIC E4754 & 1932 & $77,608,578$ & $3,602,526$ & 4.64 & PRJNA 299409 \\
\hline Peribolaster folliculatus 2 & SIO-BIC E4754 & 1621 & $40,810,648$ & $33,914,958$ & 16.89 & PRJNA 299409 \\
\hline Pisaster ochraceus & SIO-BIC E6723 & 2531 & $88,987,394$ & $3,962,217$ & 4.45 & PRJNA 299406 \\
\hline Psilaster charcoti & SIO-BIC E4755 & 2298 & $62,076,466$ & $2,705,774$ & 4.36 & PRJNA 299410 \\
\hline Pteraster tesselatus & SIO-BIC E6727 & 2381 & $63,162,964$ & $3,253,285$ & 5.15 & PRJNA 299398 \\
\hline Remaster gourdoni & SIO-BIC E4757 & 2164 & $55,504,406$ & $2,071,104$ & 3.73 & PRJNA 299412 \\
\hline Xyloplax sp. & SIO-BIC E6809 & 1440 & $61,076,078$ & $3,835,893$ & 6.28 & PRJNA 299326 \\
\hline Asterias amurensis & $--^{f}$ & 1616 & - & - & - & PRJNA 236087 \\
\hline Asterias forbesi & $-{ }^{\mathrm{f}}$ & 2291 & - & - & - & PRJNA 236087 \\
\hline Asterias rubens & $-{ }^{f}$ & 2279 & - & - & - & PRJNA 236087 \\
\hline Marthasterias glacialis & $-{ }^{\mathrm{f}}$ & 2257 & - & - & - & PRJNA 236087 \\
\hline Leptasterias sp. & $--^{f}$ & 2279 & - & - & - & PRJNA 236087 \\
\hline
\end{tabular}

No., number; sp., species; \%, percentage.

a Outgroup taxa (Class Ophiuroidea, brittlestars).

${ }^{\mathrm{b}}$ From published cDNA library, so no transcriptomic data or voucher available.

c Specimen consumed in study.

d https://www.ncbi.nlm.nih.gov/bioproject/?term = Echinotol.

e KSORC, Korea South Pacific Ocean Research Center; SIO-BIC, Scripps Institution of Oceanography Benthic Invertebrate Collection.

${ }^{\mathrm{f}}$ From Reich et al. (2015) so no quality control data or voucher available.

parameter sets (See Fig. 3) of residue overlap and sequence overlap for each of the initial dataset's 5,868 aligned orthoclusters, potentially yielding 211,248 total aligned orthoclusters $(36 * 5,868)$. The result of this process was only a fraction of the total amount of potential aligned orthoclusters due to tens of thousands of aligned orthoclusters that failed to pass through more stringent filters. When too many sequences within the aligned orthocluster were deemed highly divergent, the remaining sequences could no longer be aligned and therefore the entire orthocluster was removed. With the identification and removal of highly divergent sequences from aligned orthoclusters, a total of 60,659 possible aligned orthocluster candidates remained from the 36 different parameter combinations. BOXER was then used to identify an optimal aligned orthocluster to represent each of the 5,868 original aligned orthoclusters, based on two user-defined parameters; number of unique taxa and percentage of gap characters present in the aligned orthocluster. Of the 5,868 original aligned orthoclusters, 4,281 that had at least 13 unique taxa (50\% of the included species) and up to $95 \%$ gaps and were retained, to constitute a reduced dataset. 4,281 phylogenies were then estimated under Maximum likelihood analysis using RAxML (Stamatakis, 2014) using a CAT model of rate heterogeneity with a Jones Taylor Thornton (JTT) matrix of amino acid substitution, keeping computational efficiency in mind. 100 bootstrap replicates were performed for each retained aligned orthocluster and the tree with the highest likelihood was chosen.

\subsection{Phylogenetic analysis without paralogs}

The 4,281 aligned orthoclusters and associated gene trees were then assessed for the possible presence of paralogous sequences using Phylotreepruner (Kocot et al., 2013). After the removal of likely paralogous sequences, a locus selection test based on alignment occupancy was used to analyze each of the 4,281 alignments. This split the reduced dataset into 19 nested subsets. Each nested subset is based on total allowable gap percentage in an alignment starting at 5\% through 95\% allowable gap characters at 5\% increments. Each of the 19 nested subsets were then concatenated using FASconCAT (Kück and Meusemann, 2010). The resulting 19 concatenated (multi-locus) nested subsets were checked for all gap-only columns that were then removed using AliView (Larsson, 2014). The final nested subsets were analyzed under Maximum Likelihood using a single partition protein substitution model. The best protein substitution model for each nested subset was determined by RAxML based on the model with the highest likelihood score on the parsimony starting tree. The PROTGAMMAAUTO command determines the most appropriate protein substitution model among 21 models (Stamatakis, 2014). For each of the 19 nested subsets, 100 bootstrap replicates were performed and the tree with the highest likelihood was chosen. From the 19 topologies produced in this study, we highlight one phylogeny based on maximum average percentage bootstrap support values across asteroid nodes. The workflow used to reconstruct these phylogenies is graphically described in Fig. 4.

To derive basic details regarding the genetic composition of the included alignments, a functional analysis of the longest protein sequence from each of the 4,281 alignments was performed. To complete this task, a Biopython script was written to parse each alignment for the longest sequence, which was then used as input to InterProScan 5 (Jones et al., 2014). InterProScan 5 then returns annotations for each sequence by classifying the submitted protein sequence into families and predicting the presence of domains and important sites. Furthermore, an inquiry into the echinoderm genes included in the 4,281-locus reduced dataset was performed using BLASTP on the longest sequence per alignment as the query against the NR database. Alignments in which the longest sequence had a BLASTP hit to a protein that had not yet been described for an echinoderm were discarded. 

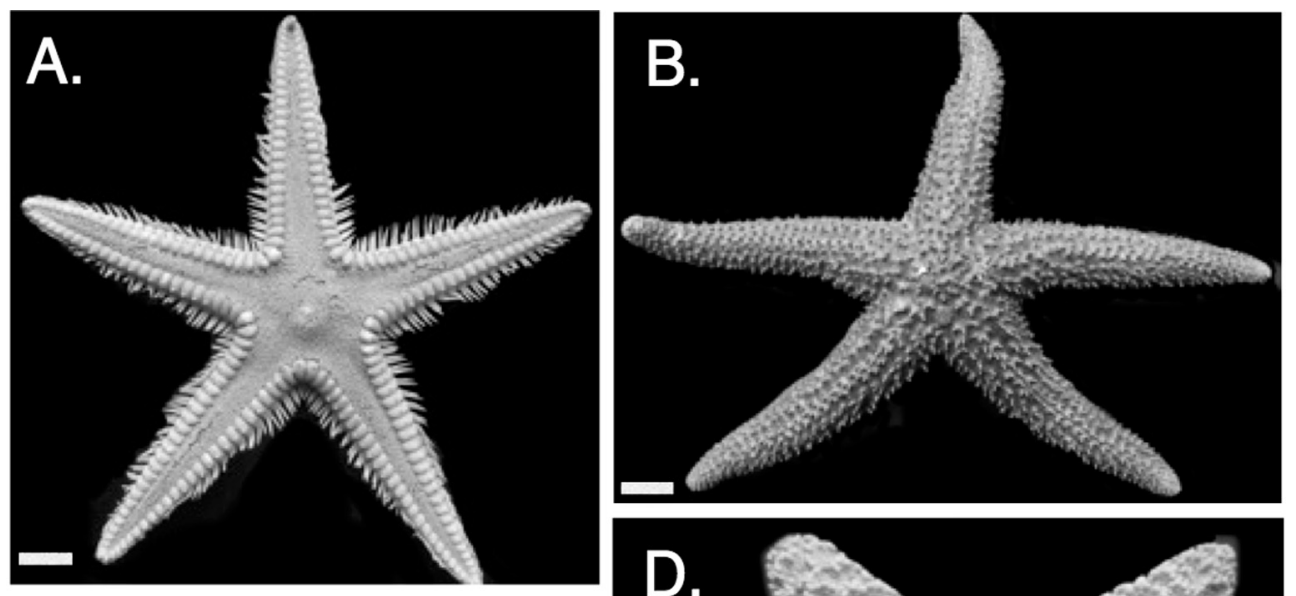

Fig. 2. Representatives from the United States National Museum of Natural History (NMNH) dry collection of some species included in the analysis. All catalog numbers are NMNH except as noted. Except for E, scale bar $=10.0 \mathrm{~mm}$. A. Astropecten duplicatus (Astropectinidae, Paxillosida) 39821. B. Echinaster spinulosus (Echinasteridae, Spinulosida) E40408. C. Glabraster antarctica (Poraniidae, "Valvatida") E13647. D. Pisaster ochraceus (Asteriidae, Forcipulatida) E21485. E. Xyloplax n. sp. (Velatida) SIO-BIC E6809. Scale Bar $=5.0 \mathrm{~mm}$. F. Pteraster tesselatus (Pterasteridae, Velatida) E1485.
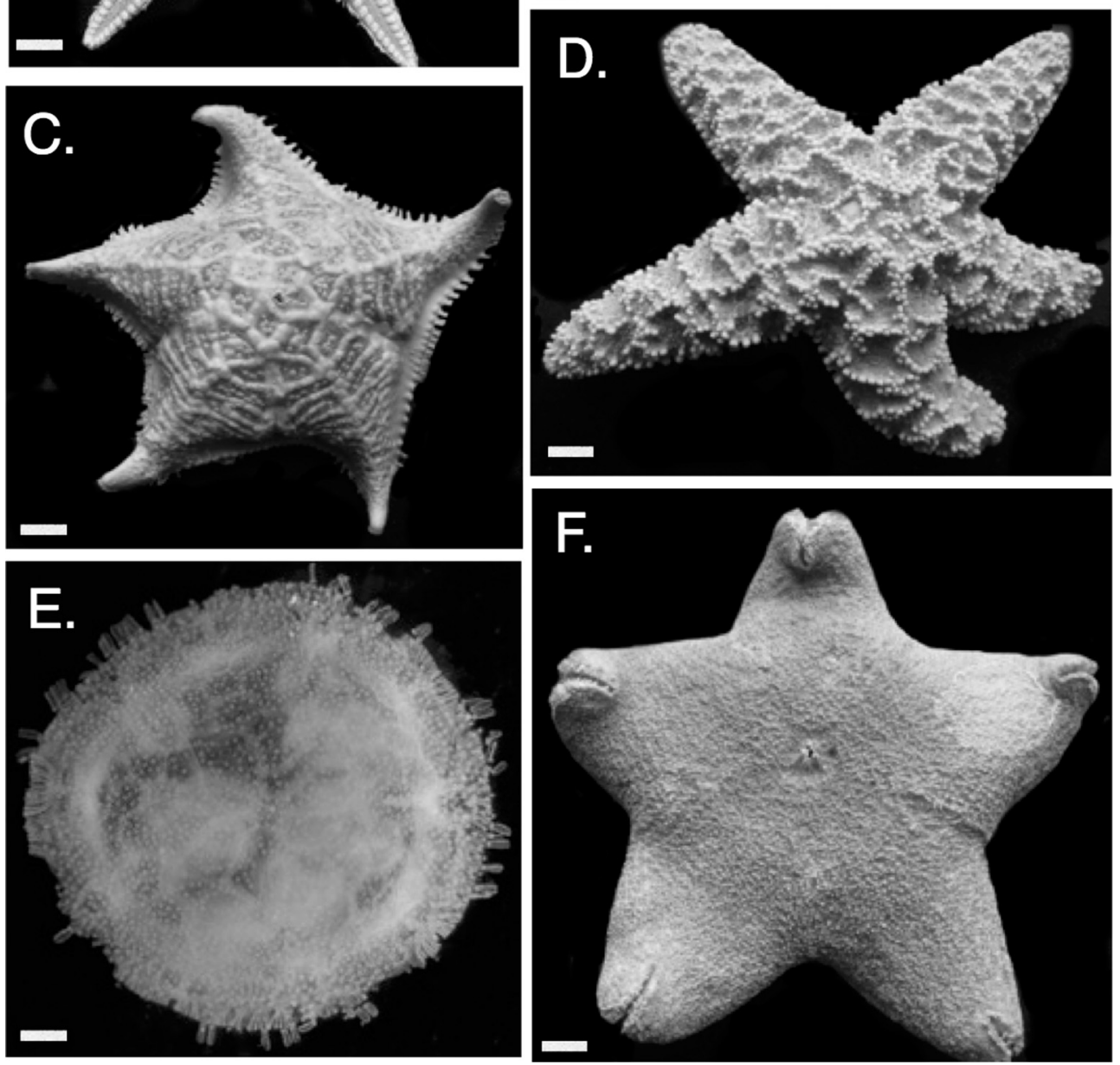

\section{Results and discussion}

\subsection{Raw data pre-processing and creation of initial and reduced datasets}

RNA-seq produced a total of $1.11 \times 10^{9}$ raw reads. The sample from Pisaster ochraceus had the largest number of raw reads at $8.90 \times 10^{7}$. The Cheiraster sp. sample had the least raw reads at $3.02 \times 10^{7}$ (see Table 2 for details). In the process of ortholog identification 93,908 orthoclusters that contained four or more taxa were detected. Taxonomic filters applied to the 93,908 orthoclusters (described in experimental procedures) yielded an initial dataset of 5,868 putative orthoclusters. Following the removal of highly divergent and paralogous sequences from the 5,868 initial aligned orthoclusters, a reduced dataset of 4,281 aligned orthoclusters was retained and later analyzed under an alignment occupancy method. The initial 5,868 aligned orthoclusters contained a total of 350,182 sequences; following the removal of paralogous sequences the reduced dataset of 4,281 aligned orthoclusters contained 64,749 sequences.

\subsection{Creation of nested data subsets}

BOXER divided the 4,281 aligned orthoclusters into 19 nested data subsets of concatenated, aligned orthoclusters based on allowed gap characters, from $5 \%$ to $95 \%$ at $5 \%$ increments. The topology presented in all the 19 nested subsets placed Xyloplax as a velatid asteroid. These 19 data subsets and their corresponding topologies are available at http://echinodb.uncc.edu/. 18 of the 19 nested subsets (5-90\% allowable gap characters) placed Xyloplax as sister to Pteraster, while the most permissive or inclusive subset ( $95 \%$ allowable gap characters) placed it as sister to the Velatida (represented by Pteraster, Remaster, and Peribolaster). Considering the technical replication strategy, Peribolaster 1 and Peribolaster 2 were consistently recovered as sister 


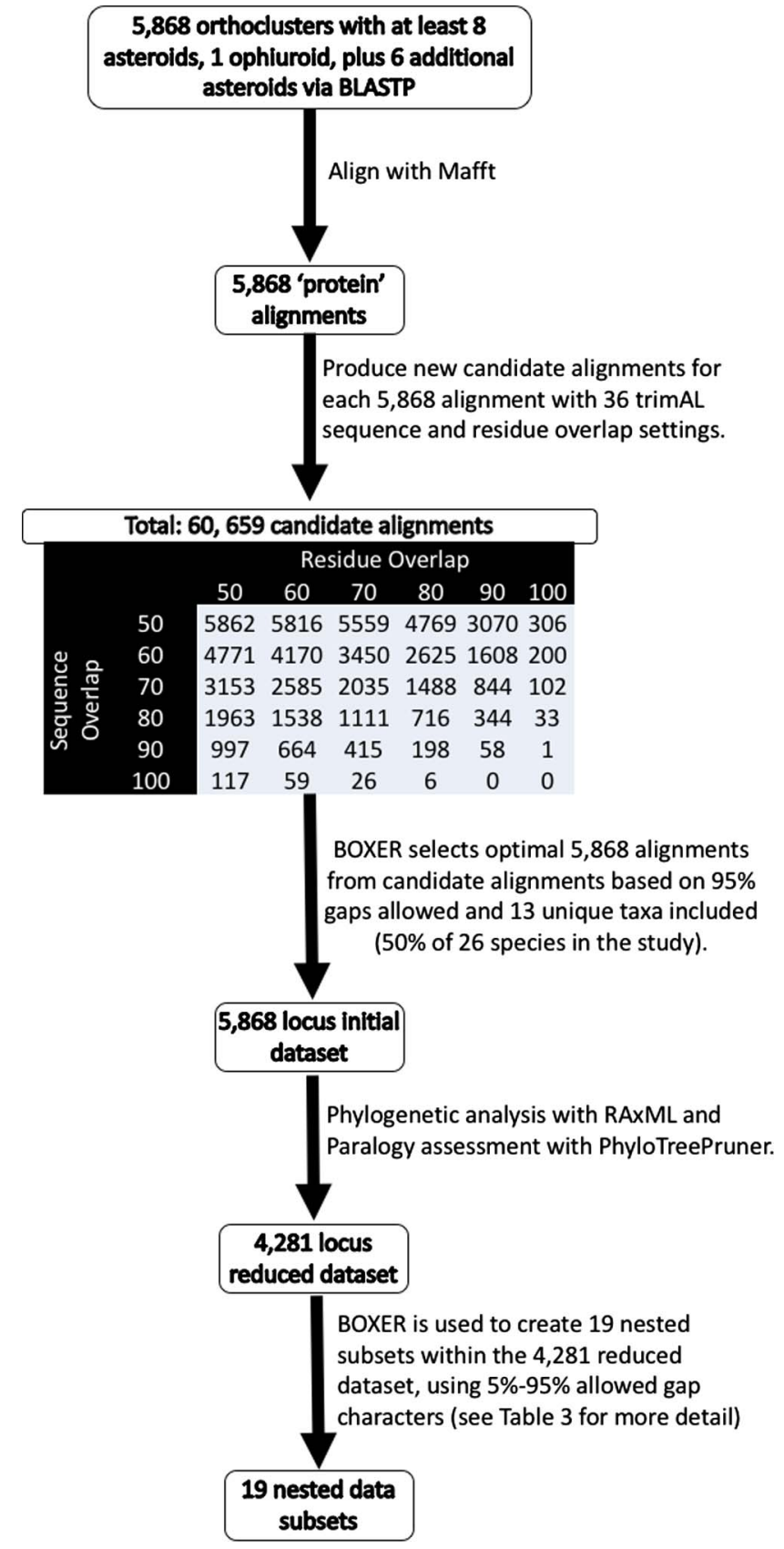

Fig. 3. The process of selecting alignments using the TrimAL and BOXER programs.

taxa in all nested subsets. Of the 19 topologies derived from BOXER, 18 trees consistently recovered ordinal-level monophyly for Paxillosida, Forcipulatida, Velatida and Spinulosida (See Table 3). From these 18 topologies, we highlight the tree that resulted from the nested subset that allowed for $60 \%$ gaps and at least 13 unique taxa as it was the only one that produced $100 \%$ bootstrap support values for all asteroid nodes (Fig. 5). This topology recovered monophyly for many asteroid orders with 100\% bootstrap support. Well-supported clades included Velatida, Paxillosida, Forcipulatida, Forcipulatida + Brisingida (i.e., the Forcipulatacea), Forcipulatacea sister to Velatida, Spinulosida and Paxillosida + Notomyotida. These results are consistent with the work of Janies et al. (2011) based on Sanger sequencing. One traditional order that was not monophyletic was Valvatida. The remaining trees resulting from the parameter variation are largely consistent with the highlighted tree (see Table 3).

The topology of the outgroup is incongruent with recent studies that sampled brittle stars well (O'Hara et al., 2014; Hugall et al., 2016; O'Hara et al., 2017). These studies placed Astrophyton as sister to the three remaining ophiuroids. Our result is likely a function of too little sampling of ophiuroids, which we included only to form an outgroup.

\subsection{Orthocluster alignment annotation}

The 4,281 aligned orthoclusters were annotated using InterproScan 5 which generated InterproScan descriptions and Gene Ontology (GO) identifiers as output. These identifiers define concepts and classes that describe gene function and relationships between them. Of the 4,281 loci, 3,109 were associated with at least one GO ID and 3,935 were associated with an Interpro accession and description. This list of annotated orthoclusters and their descriptions are included in supplementary Table 1 . The 4,281 aligned orthoclusters were also screened for described echinoderm genes. This was performed via a BLASTP search on the longest sequence in the aligned orthocluster against the RefSeq non-redundant protein database. This process removed 446 nonechinoderm aligned orthoclusters from the 4,281 aligned orthoclusters, leaving 3,833 . The remaining 3,833 aligned orthoclusters were then concatenated and analyzed under maximum likelihood. The resulting maximum likelihood tree did not differ in topology from the 4,281 locus reduced dataset analysis (details not shown).

\subsection{Xyloplax}

As outlined earlier, since its discovery, the phylogenetic position of Xyloplax has been controversial, although molecular phylogenetic analyses have always placed it within the Asteroidea (Janies and Mooi, 1998; Janies, 2001; Janies et al., 2011; Janies, 2013). Affinities with velatid asteroids based on developmental models, especially based on comparisons with Pteraster, have been argued by Janies and McEdward (1994a, 1994b). The specifics of those ontogenetic inferences were revised with new embryological data on Xyloplax by Janies et al. (2011). Our highlighted tree (Fig. 5) placed Xyloplax as sister to Pteraster. Moreover, Xyloplax is recovered as a Velatid asteroid across parameter space (Table 3). An affinity between Xyloplax and the deep-sea Caymanostella as argued by Smith (1988) and Belyaev (1990) was not assessed here. In 2011, Janies et al. showed that Caymanostella was not closely related to Pteraster or Xyloplax.

\subsection{The Velatida}

The tree presented in Fig. 5 supported the monophyly of the Velatida, inclusive of Xyloplax, the Pterasteridae and the Korethrasteridae in agreement with several prior, but disparate accounts. The Velatida as originated by Perrier (1894) and Fisher (1930) included the Pterasteridae and the Myxasteridae. Blake's (1987) phylogenetic analysis of asteroid morphology returned the Velatida into usage. Blake's analysis showed Velatida as composed of the Pterasteridae, Korethrasteridae and Myxasteridae as well as the Solasteridae and Caymanostellidae. Molecular work by Mah and Foltz (2011b) further restricted the Velatida to the Pterasteridae, Korethrasteridae and the Myxasteridae and moved the Solasteridae to the Valvatida. Work by Janies et al. (2011) had the same result but lacked Myxasteridae. Although placed within the Velatida by Blake (1987), the Caymanostellidae displays affinities with other groups, such as the Asterinidae, and its phylogenetic position remains untested by phylogenomic methods. A morphological-fossil phylogenetic survey by Gale (2011) adopted a more traditional classification and placed Remaster and Pteraster as members of the Spinulosida, a paraphyletic grouping which has failed to find support from either morphology (e.g. Blake, 1987) or molecules (Mah and Foltz, 2011b). Janies et al. (2011) were the first to show Xyloplax as a member of the Velatida, as part of a clade that contained two pterasterids, Pteraster and Hymenaster, but lacked other velatids. In this study, we included the korethrasterids Peribolaster and Remaster. 


\section{Phylotranscriptomic Analysis of Extant Starfish Workflow}

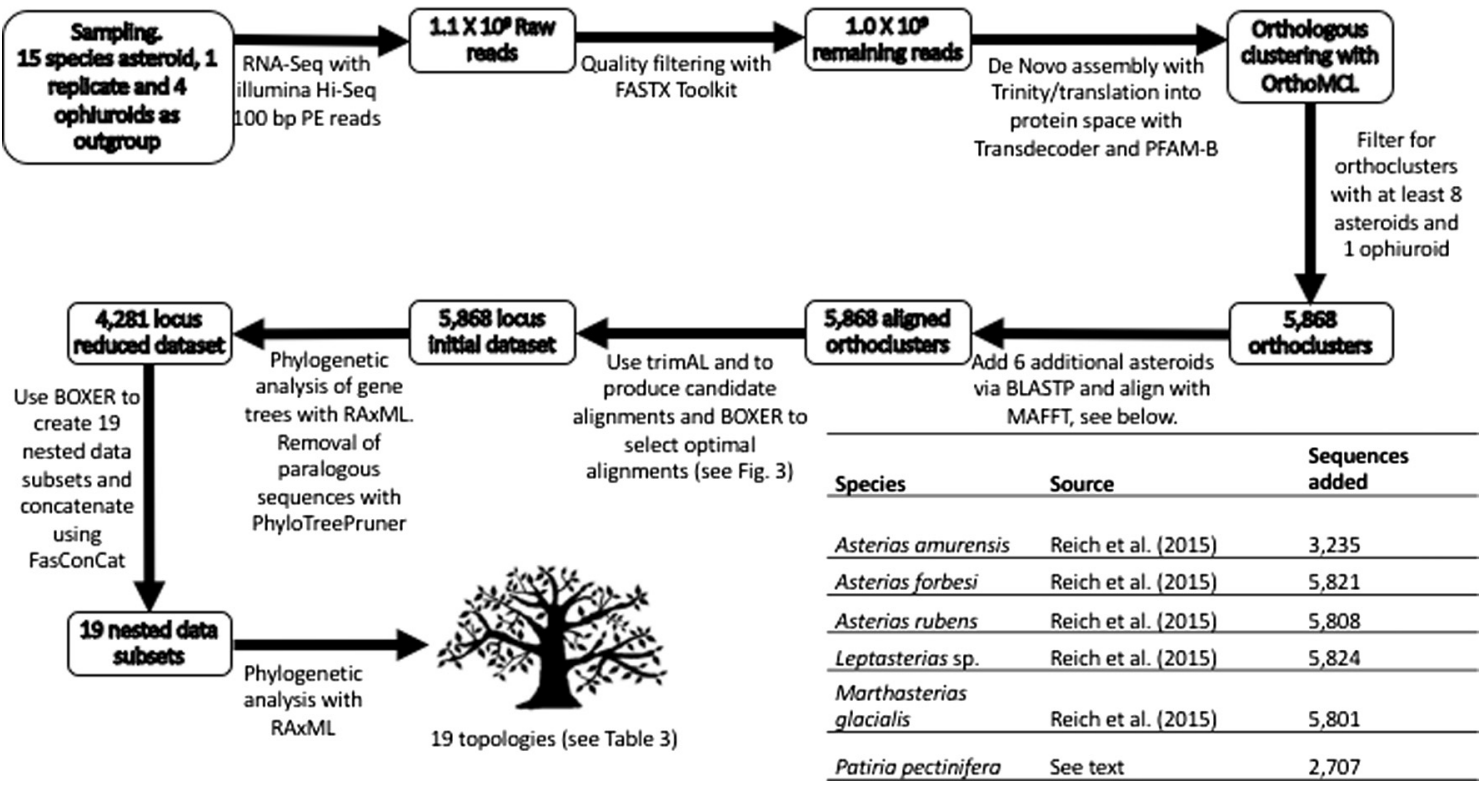

Fig. 4. A simple graphical representation of phylogeny reconstruction from sample collection to tree creation.

Table 3

This table contains a topology summary for the nested data subsets included in this study. Columns (left to right) include: \% gap criterion for inclusion in the nested data subset, number of loci in each dataset, orders recovered as monophyletic in the RaxML analysis, $\%$ gap characters in alignment, inserted $\mathrm{N} / \mathrm{X}$ in the concatenated alignment, pairwise identity, and alignment length.

\begin{tabular}{|c|c|c|c|c|c|c|}
\hline $\begin{array}{l}\text { Nested } \\
\text { subset } \\
\text { [\% gaps } \\
\text { allowed] }\end{array}$ & $\begin{array}{l}\text { No. } \\
\text { of } \\
\text { loci }\end{array}$ & $\begin{array}{l}\text { Orders that } \\
\text { are } \\
\text { monophyletic }{ }^{\text {a }}\end{array}$ & Gaps [\%] & $\begin{array}{l}\text { Inserted } \\
\mathrm{N} \text { or } \mathrm{X} \\
{[\%]}\end{array}$ & $\begin{array}{l}\text { Pairwise } \\
\text { identity } \\
{[\%]}\end{array}$ & 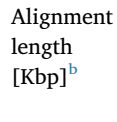 \\
\hline 5 & 37 & $\mathrm{P}^{\mathrm{c}}$ & 0.10 & 38.96 & 36.1 & 7.360 \\
\hline 10 & 48 & $\mathrm{P}^{\mathrm{c}}, \mathrm{Ve}, \mathrm{S}$ & 0.37 & 40.79 & 33.7 & 9.955 \\
\hline 15 & 145 & $P, F, V e, S$ & 2.25 & 41.77 & 30.1 & 34.002 \\
\hline 20 & 371 & $P, F, V e, S$ & 3.71 & 41.62 & 28.6 & 91.125 \\
\hline 25 & 651 & $\mathrm{P}, \mathrm{F}, \mathrm{Ve}, \mathrm{S}$ & 5.04 & 42.35 & 26.7 & 171.320 \\
\hline 30 & 1012 & $\mathrm{P}, \mathrm{F}, \mathrm{Ve}, \mathrm{S}$ & 6.36 & 42.84 & 24.9 & 285.890 \\
\hline 35 & 1342 & $\mathrm{P}, \mathrm{F}^{\mathrm{d}}, \mathrm{Ve}, \mathrm{S}$ & 7.53 & 42.97 & 23.7 & 402.754 \\
\hline 40 & 1671 & $\mathrm{P}, \mathrm{F}^{\mathrm{d}}, \mathrm{Ve}, \mathrm{S}$ & 8.78 & 42.99 & 22.6 & 531.031 \\
\hline 45 & 1958 & $\mathrm{P}, \mathrm{F}, \mathrm{Ve}, \mathrm{S}$ & 10.25 & 42.57 & 21.7 & 660.666 \\
\hline 50 & 2233 & $\mathrm{P}, \mathrm{F}, \mathrm{Ve}, \mathrm{S}$ & 11.80 & 42.18 & 20.7 & 794.603 \\
\hline 55 & 2471 & $\mathrm{P}, \mathrm{F}, \mathrm{Ve}, \mathrm{S}$ & 13.33 & 41.76 & 19.9 & 920.902 \\
\hline $60^{\mathrm{e}}$ & 2683 & $\mathrm{P}, \mathrm{F}, \mathrm{Ve}, \mathrm{S}$ & 14.68 & 41.48 & 19.2 & 1036.409 \\
\hline 65 & 2929 & $\mathrm{P}, \mathrm{F}, \mathrm{Ve}, \mathrm{S}$ & 16.11 & 41.38 & 18.3 & 1172.960 \\
\hline 70 & 3198 & $\mathrm{P}, \mathrm{F}, \mathrm{Ve}, \mathrm{S}$ & 18.00 & 41.24 & 17.2 & 1343.339 \\
\hline 75 & 3523 & $P, F, V e, S$ & 19.95 & 41.41 & 16.0 & 1551.577 \\
\hline 80 & 3984 & $\mathrm{P}, \mathrm{F}, \mathrm{Ve}, \mathrm{S}$ & 22.07 & 41.48 & 14.7 & 1811.425 \\
\hline 85 & 4163 & $\mathrm{P}, \mathrm{F}, \mathrm{Ve}, \mathrm{S}$ & 23.70 & 41.45 & 13.8 & 2027.010 \\
\hline 90 & 4249 & $\mathrm{P}, \mathrm{F}, \mathrm{Ve}, \mathrm{S}$ & 24.29 & 41.44 & 13.4 & 2107.727 \\
\hline 95 & 4281 & $\mathrm{P}, \mathrm{F}, \mathrm{Ve}, \mathrm{S}$ & 24.58 & 41.36 & 13.3 & 2141.743 \\
\hline
\end{tabular}

${ }^{\mathrm{a}} \mathrm{P}=$ Paxillosida, $\mathrm{Ve}=$ Velatida, $\mathrm{S}=$ Spinulosida, $\mathrm{F}=$ Forcipulatida; Valvatida was never recovered as monophyletic.

b This is the length of the concatenated alignment analyzed in RAxML.

c Includes Cheiraster (Notomyotida).

${ }^{\mathrm{d}}$ Includes Odinella (Brisingida).

e Indicates our highlighted data subset, for which we observed monophyletic orders with consensus to $18 / 19$ datasets. This data subset is unique among all rows in having $100 \%$ bootstrap support at all asteroid nodes.

\subsection{The Forcipulatacea}

The monophyly of the forcipulataceans (Forcipulatida + Brisingida) has been the least controversial of the major asteroid groups. The distinctive morphology of forcipulates has always set them apart in traditional taxonomy (e.g. Fisher, 1928; Fisher, 1930), and they have usually been supported as monophyletic in both morphologybased cladistic analyses (e.g. Blake, 1987; Gale, 1987) and molecular phylogenetic studies (e.g. Knott and Wray, 2000; Foltz et al., 2007; Janies et al., 2011; Mah and Foltz, 2011a). The position of the Forcipulatacea relative to other asteroids in Fig. 5 disagreed with the topology of Gale (2011) who embedded the forcipulates among other valvatidans within his "Tripedicellaria" clade, a relationship which has never been observed in prior literature (Blake and Mah, 2014).

\subsection{The Poraniidae}

One phylogenetic result in Fig. 5 is the position of the Glabraster antarctica, a poraniid, as sister to the clade containing the Notomyotida, the Spinulosida, and the Paxillosida and an assemblage of taxa usually considered valvatids. Mah and Foltz (2011b) reported a similar position of the Poraniidae from their analysis of the Valvatacea. The traditional taxonomic placement of the Poraniidae has been among either the Valvatida (e.g. Blake, 1987) or the Spinulosida (Gale, 2011; Spencer and Wright, 1966). As part of his phylogenetic treatment of the Triassic poraniid, Noriaster, Blake et al. (2000) suggested that poraniids might lie outside these taxa, contrary to traditional placement. However, Blake et al. (2000) expressed uncertainty in morphological interpretation, due to the role of homeomorphy and the thick tissue overlying the skeleton in poraniids.

\subsection{The Spinulosida, Patiria, and Asteropsis}

Our highlighted tree shows Patiria and Asteropsis as sister to the Spinulosida (Henricia and Echinaster), a result similar to that seen in the recent phylogenomic study by Reich et al. (2015). We treated the Valvatida herein sensu Blake (1987) and Mah and Foltz (2011b), which verified the inclusion of the Asterinidae and the Asteropseidae within the Valvatida. Although non-monophyletic, in several recent molecular studies, Valvatida contains the highest number of species of all recent Asteroidea (Mah and Blake, 2012). Past treatments of Valvatida (e.g. Spencer and Wright, 1966) have included different taxa.

Many traditional classifications, such as Fisher (1911) and Spencer and Wright (1966), list the Echinasteridae and the Asterinidae as members of the Spinulosida, a group which has most recently been restricted to include only the Echinasteridae (Blake, 1987; Clark, 1996). 


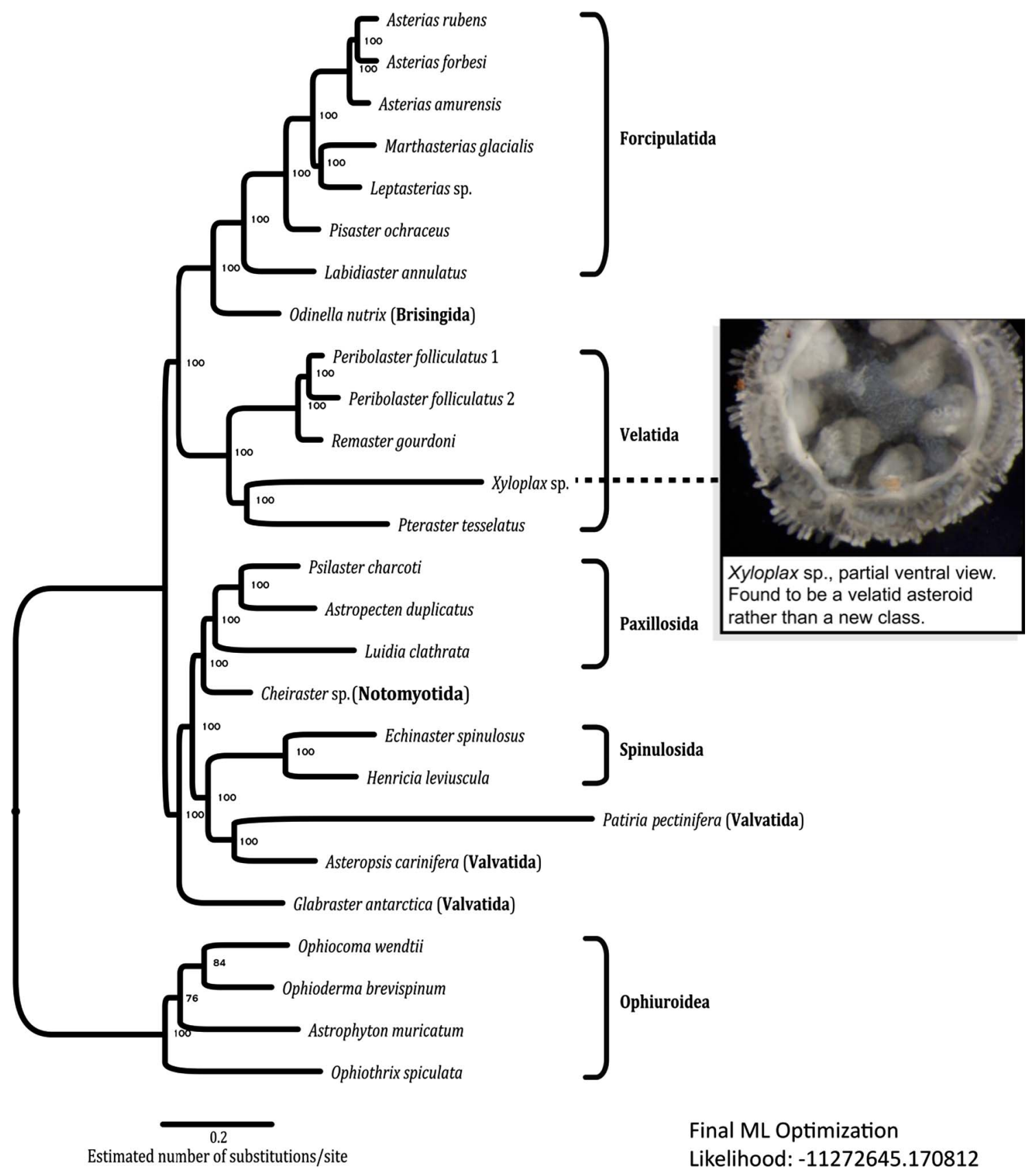

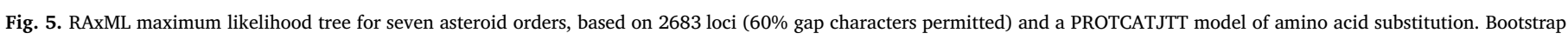
values based on 100 pseudoreplicates are shown at nodes.

Gale's (1987) non-cladistic phylogeny embedded both the Echinasteridae and the Asterinidae on distant clades within the Valvatida. The molecular treatments of Wada et al. (1996) and Matsubara et al. (2004) included only Henricia in their analyses, a genus that was placed in varied positions on their trees. Wada et al. (1996) and Matsubara et al. (2004) also included several species of the Asterinidae which (although monophyletic) were consistently reconstructed as the sister clade to the Asteriidae (Forcipulatacea). This relationship has not been reproduced by other studies with comparable taxon sampling. LaFay et al. (1995) produced a combined morphological and molecular analysis (using a single gene) that supported Echinaster and Henricia as a clade that displayed highly variable relationships with other asteroid taxa. Knott and Wray's (2000) results based on Sanger sequencing showed a paraphyletic Spinulosida based on Echinaster and Henricia. Asterinids were recovered on distant branches away from the echinasterids in the Knott and Wray (2000) tree. The Gale (2011) morphological analysis supported Echinaster as the sister clade to the Forcipulatida with Asterina as a member of a phylogenetically distant, non-valvatidan "Spinulosida." Trees from Janies et al. (2011) supported a monophyletic Spinulosida and a paraphyletic Valvatida.

\subsection{The Paxillosida and Notomyotida}

Our highlighted tree (Fig. 5) placed the Paxillosida as sister to Cheiraster sp. (representing the Benthopectinidae); within the Paxillosida, Luidia was supported as the sister clade to Astropecten $+P s i-$ laster. This group was sister to a group that included the Spinulosida and two valvatids (Fig. 5). The tree exhibits a long terminal branch for Patiria pectinifera, which is likely a result of the different data source from which the Patiria sequences were derived (EST from embryonic tissue vs. de novo transcriptomes from adult tissue). Overall, Fig. 5 resembled Mah and Foltz's (2011b) two-locus tree, which included the 
Paxillosida (Astropectinidae and Luidiidae) and Notomyotida as members of the same clade. The Mah and Foltz (2011b) tree included taxa traditionally considered as Paxillosida, including the Astropectinidae, Luidiidae, Goniopectinidae and Ctenodiscidae, but also the Pseudarchasteridae, which had previously been classified within the Goniasteridae.

As summarized in the introduction, Paxillosida is central to longstanding questions concerning the cladogenetic events that gave rise to extant asteroid lineages. Our tree represents one of the first well-sampled (for taxa and loci), well-supported phylogenomic evidence of crown-group asteroid phylogeny. In our result, the earliest cladogenetic event among extant asteroids separated Velatida + Forcipulatacea from the Spinulosida and Valvatacea.

Fig. 5 showed the Paxillosida and the Spinulosida as later diverging lineages within a Valvatacea + Spinulosida clade. If allowance is made for the position of the Velatida, the tree topology in Fig. 5 is nearly identical to that of Blake (1987), who has consistently argued for a latediverging Paxillosida (e.g., Blake and Mah, 2014). Our results are similar to those of Mah and Foltz (2011b); however, their tree did not survey echinasterids, nor did they employ outgroup rooting (see Fig. 1). The phylogenetic results of Blake (1987), Mah and Foltz (2011b) and Fig. 5 are all consistent with a "Paxillosida is derived" scenario which counters the "Paxillosida is primitive" perspective of Mortensen (1922,1923), Fell (1962a, 1962b), LaFay et al. (1995), Wada et al. (1996) and Gale (1987, 2011). The "Paxillosida is primitive" scenario was originally based on the assumption that the absence of brachiolaria larvae and suckered tube feet in the extant Paxillosida was the plesiomorphic condition for asteroids (Mortensen, 1922) and was later augmented with fossil data (Fell, 1962a, 1962b; Gale, 1987, 2011). The "Paxillosida is derived" scenario, as outlined by MacBride (1921, 1923a, 1923b) and Blake $(1987,1988)$ argued that larval morphology and fossil and living skeletal characters observed in the Paxillosida were adaptations for living on unconsolidated sediment, such as sand or mud.

\section{Conclusions}

The results presented in this study are robust to a wide spectrum of alignment parameter variation, concomitant locus selection variation, and technical replication of known velatids. Of the 19 topologies derived from BOXER, 18 trees consistently recovered ordinal-level monophyly for Paxillosida, Forcipulatida, Velatida and Spinulosida. We highlighted a phylogeny from the concatenated aligned orthoclusters that allowed for $60 \%$ gaps and at least 13 unique taxa on the basis of bootstrap support values of all asteroid nodes being $100 \%$, a unique feature of this alignment with respect to the others (Fig. 5). This tree recovers monophyly for many asteroid taxa with nodes containing high bootstrap support from well-supported clades including: Velatida, Paxillosida, Forcipulatida, Forcipulatida + Brisingida, Forcipulatida + Brisingida sister to Velatida, Paxillosida + Notomyotida. The topology of the outgroup species however, was incongruent with recent studies that included ophiuroids (O'Hara et al., 2014; Hugall et al., 2016; O'Hara et al., 2017). This discrepancy can be best explained by the scope of the present study, which focused on relationships within the asteroid class. This study does not attempt to propose a new ophiuroid topology based on only four species. Furthermore, the loci included in this study were filtered based on the inclusion of at least 13 asteroids and only one ophiuroid, without regard for ophiuroid diversity. The ambiguity observed in this clade would benefit from further studies that include representatives from all extant echinoderm classes.

In regards to asteroid phylogeny, these results and the results of Janies et al. (2011) support the hypothesis of non-monophyly of Valvatida. This result implies that more work is warranted to investigate the diversity of groups assigned to Valvatida using transcriptomics and genomics technologies.
The results of this study support the inclusion of Xyloplax as a velatid asteroid. This result implies that asteroid morphology remains labile well beyond the establishment of the body plan of the group. Next steps require the means to understand the mechanistic underpinnings of drastic changes of morphology. Xyloplax is a rare deep-sea species and thus not a very tractable as a model organism. The challenge is to develop models among shallow-water echinoderm species with highly labile embryogenesis and life cycles (e.g. some members of the Pterasteridae).

\section{Acknowledgments}

We thank Ben Grupe, Brian Livingstone and Jim Nestler for collecting some of the specimens and Dan Blake, Professor Emeritus, the University of Illinois at Urbana-Champaign for useful discussions. We also thank the University of North Carolina Research Computing Team and the Department of Bioinformatics and Genomics for ongoing support.

\section{Funding}

This material is based upon work was supported by the National Science Foundation of the United States (www.nsf.gov) under Award Nos. DEB 1036416 to D.A.J., DEB 1036358 to D.W.F. and C.L.M., DEB 1036368 to G.W.R. and DEB 1036366 to G.A.W and ANT 1043749 to N.G.W and G.W.R and Ron Burton. The funders had no role in study design, data collection and analysis, decision to publish, or preparation of the manuscript.

\section{Appendix A. Supplementary material}

Supplementary data associated with this article can be found, in the online version, at http://dx.doi.org/10.1016/j.ympev.2017.07.022.

\section{References}

Baker, A.N., Rowe, F.W.E., Clark, H.E.S., 1986. A new class of Echinodermata from New Zealand. Nature 321, 862-864. http://dx.doi.org/10.1038/321862a0.

Belyaev, G.M., 1900. Is it valid to isolate the genus Xyloplax as an independent class of echinoderms? Zool. Zhurnal 83-96.

Blake, D.B., 1972. Sea star Platastenras: ossicle morphology and taxonomic position. Science 176, 306-307. http://dx.doi.org/10.1126/science.176.4032.306.

Blake, D.B., 1987. A classification and phylogeny of post-Palaeozoic sea stars (Asteroidea: Echinodermata). J. Nat. Hist. 21, 481-528. http://dx.doi.org/10.1080/ 00222938700771141.

Blake, D.B., Mah, C.L., 2014. Comments on "the phylogeny of post-Palaeozoic Asteroidea (Neoasteroidea, Echinodermata)" by A.S. Gale and perspectives on the systematics of the Asteroidea. Zootaxa 3779, 177-194.

Blake, D.B., Tintori, A., Hagdorn, H., 2000. A Nee, early crown-group asteroid (Echinodermata) from the Norian (TRIASSIC) of Northern Italy. Riv. Ital. di Paleontol. e Stratigr. (Research Paleontol. Stratigr.) 106. http://dx.doi.org/10. 13130/2039-4942/5395.

Blake, D., 1988. Paxillosidans are not primitive asteroids: A hypothesis based on functional considerations. In: Burke, R., Mladenov, P., Lambert, P., R.L., P. (Eds.), Echinoderm Biology. Balkema, Rotterdam, pp. 309-314.

Cannon, J.T., Kocot, K.M., Waits, D.S., Weese, D.A., Swalla, B.J., Santos, S.R., Halanych, K.M., 2014. Phylogenomic resolution of the hemichordate and echinoderm clade. Curr. Biol. 24, 2827-2832. http://dx.doi.org/10.1016/j.cub.2014.10.016.

Capella-Gutiérrez, S., Silla-Martínez, J.M., Gabaldón, T., 2009. TrimAl: a tool for automated alignment trimming in large-scale phylogenetic analyses. Bioinformatics 25 , 1972-1973. http://dx.doi.org/10.1093/bioinformatics/btp348.

Clark, A.M., 1996. An index of names of recent Asteroidea Part 3: Velatida and Spinulosida. Echinoderm Studies 5, 183-250.

Fell, H.B., 1962a. A surviving somasteroid from the Eastern Pacific Ocean. Science 136 633 LP-636.

Fell, H.B., 1962b. A living somasteroid, platasterias latiradiata Gray. Univ. Kansas Paleontol. Contrib. 1-16.

Fell, H.B., 1963. The phylogeny of sea-stars. Philos. Trans. R. Soc. Lond. B. Biol. Sci. 246 381 LP-435.

Feuda, R., Smith, A.B., 2015. Phylogenetic signal dissection identifies the root of starfishes. PLoS ONE 10, e0123331.

Finn, R.D., Mistry, J., Tate, J., Coggill, P., Heger, A., Pollington, J.E., Gavin, O.L., Gunasekaran, P., Ceric, G., Forslund, K., Holm, L., Sonnhammer, E.L.L., Eddy, S.R., Bateman, A., 2010. The Pfam protein families database. Nucl. Acids Res. 38, D211-D222. 
Fisher, W.K., 1911. Asteroidea of the North Pacific and adjacent waters. Bull. United States Natl. Museum 76, 1-420.

Fisher, W.K., 1928. Asteroidea of the North Pacific and adjacent waters pt. 2: Forcipulata (part). Bull. United States Natl. Museum 76, 1-245. http://dx.doi.org/10.5479/si. 03629236.76.2.

Fisher, W.K., 1930. Asteroidea of the North Pacific and adjacent waters pt. 3: Forcipulata (concluded). Bull. United States Natl. Museum 1-356. http://dx.doi.org/10.5479/si. 03629236.76 .3$.

Foltz, D.W., Bolton, M.T., Kelley, S.P., Kelley, B.D., Nguyen, A.T., 2007. Combined mitochondrial and nuclear sequences support the monophyly of forcipulatacean sea stars. Mol. Phylogenet. Evol. 43, 627-634. http://dx.doi.org/10.1016/j.ympev.2006. 10.012 .

Gale, A.S., 2013. Phylogeny of the Asteroidea. In: Lawrence, J.M. (Ed.), Starfish: Biology and Ecology of the Asteroidea. Johns Hopkins University Press, Baltimore, pp. 3-14.

Gale, A.S., 1987. Phylogeny and classification of the Asteroidea (Echinodermata). Zool. J. Linn. Soc. 89, 107-132. http://dx.doi.org/10.1111/j.1096-3642.1987.tb00652.x.

Gale, A.S., 2011. The Phylogeny of Post-Palaeozoic Asteroidea (Neoasteroidea, Echinodermata). Spec. Pap. Palaeontol. 5-112.

Haas, B.J., Papanicolaou, A., Yassour, M., Grabherr, M., Blood, P.D., Bowden, J., Couger, M.B., Eccles, D., Li, B., Lieber, M., Macmanes, M.D., Ott, M., Orvis, J., Pochet, N., Strozzi, F., Weeks, N., Westerman, R., William, T., Dewey, C.N., Henschel, R., Leduc, R.D., Friedman, N., Regev, A., 2013. De novo transcript sequence reconstruction from RNA-seq using the Trinity platform for reference generation and analysis. Nat. Protoc. 8, 1494-1512. http://dx.doi.org/10.1038/nprot.2013.084.

Hugall, A.F., O'Hara, T.D., Hunjan, S., Nilsen, R., Moussalli, A., 2016. An exon-capture system for the entire class ophiuroidea. Mol. Biol. Evol. 33, 281-294. http://dx.doi. org/10.1093/molbev/msv216.

Janies, D.A., McEdward, L.R., 1994a. A hypothesis for the evolution of the concentricycloid water-vascular system. In: Reproduction and Development of Marine Invertebrates: Papers from a Symposium Held at Friday Harbor Laboratories of the University of Washington, June 9-11, pp. 246-257.

Janies, D.A., McEdward, L.R., 1994b. Heterotrophy, pelagic direct development, and new body plans in velatid asteroids. In: David, B., Guille, A., Feral, J.P., Roux, M. (Eds.), Echinoderms Through Time. Balkema, Rotterdam, pp. 319-324.

Janies, D., 2001. Phylogenetic relationships of extant echinoderm classes. Can. J. Zool. 79, 1232-1250. http://dx.doi.org/10.1139/z00-215.

Janies, D.A., Voight, J.R., Daly, M., 2011. Echinoderm phylogeny including Xyloplax, a progenetic asteroid. Syst. Biol. 60, 420-438. http://dx.doi.org/10.1093/sysbio/ syr044.

Janies, D.A., 2013. Xyloplax. In: McGraw-Hill Yearbook of Science \& Technology. McGraw-Hill Education.

Janies, D., Mooi, R., 1998. Xyloplax is an asteroid. Echinoderm Res. 311-316.

Jones, P., Binns, D., Chang, H.-Y., Fraser, M., Li, W., McAnulla, C., McWilliam, H., Maslen, J., Mitchell, A., Nuka, G., Pesseat, S., Quinn, A.F., Sangrador-Vegas, A., Scheremetjew, M., Yong, S.-Y., Lopez, R., Hunter, S., 2014. InterProScan 5: genomescale protein function classification. Bioinformatics 30, 1236-1240. http://dx.doi. org/10.1093/bioinformatics/btu031.

Katoh, K., 2002. MAFFT: a novel method for rapid multiple sequence alignment based on fast Fourier transform. Nucl. Acids Res. 30, 3059-3066. http://dx.doi.org/10.1093/ nar/gkf436.

Knott, K.E., Wray, G.A., 2000. Controversy and consensus in asteroid systematics: new insights to ordinal and familial relationships. Am. Zool. 40, 382-392. http://dx.doi. org/10.1093/icb/40.3.382.

Kocot, Moroz, L., Citarella, M., Halanych, K., 2013. PhyloTreePruner: a phylogenetic treebased approach for selection of orthologous sequences for phylogenomics. Evol. Bioinf. 429. http://dx.doi.org/10.4137/EBO.S12813.

Kück, P., Meusemann, K., 2010. FASconCAT: convenient handling of data matrices. Mol. Phylogenet. Evol. 56, 1115-1118. http://dx.doi.org/10.1016/j.ympev.2010.04.024.

Lafay, B., Smith, A.B., Christen, R., 1995. A combined morphological and molecular approach to the phylogeny of asteroids (Asteroidea: Echinodermata). Syst. Biol. 44, 190-208. http://dx.doi.org/10.1093/sysbio/44.2.190.

Larsson, A., 2014. AliView: a fast and lightweight alignment viewer and editor for large datasets. Bioinformatics 30, 3276-3278. http://dx.doi.org/10.1093/bioinformatics/ btu531.

Li, L., 2003. OrthoMCL: identification of ortholog groups for eukaryotic genomes. Genome Res. 13, 2178-2189. http://dx.doi.org/10.1101/gr.1224503.

Macbride, E.W., 1923a. Echinoderm larvae and their bearing on classification. Nature 111http://dx.doi.org/10.1038/111047a0. 47-47.

Macbride, E.W., 1923b. Echinoderm larvae and their bearing on classification (reply). Nature 111, 323-324. http://dx.doi.org/10.1038/111323a0.

Macbride, E.W., 1921. Echinoderm larvæ and their bearing on classification. Nature 108, 529-530. http://dx.doi.org/10.1038/108529c0.

Madsen, F.J., 1966. The recent sea-star platasterias and the fossil Somasteroidea. Nature 209http://dx.doi.org/10.1038/2091367a0. 1367-1367.

Mah, C.L., 2006. A new species of Xyloplax (Echinodermata: Asteroidea: Concentricycloidea) from the northeast Pacific: comparative morphology and a reassessment of phylogeny. Invertebr. Biol. 125, 136-153. http://dx.doi.org/10.1111/ j.1744-7410.2006.00048.x.

Mah, C.L., Blake, D.B., 2012. Global diversity and phylogeny of the asteroidea (Echinodermata). PLoS ONE 7, e35644. http://dx.doi.org/10.1371/journal.pone. 0035644.

Mah, C.L., Foltz, D.W., 2014. New taxa and taxonomic revisions to the Poraniidae
(Valvatacea; Asteroidea) with comments on feeding biology. Zootaxa 3795, 327. http://dx.doi.org/10.11646/zootaxa.3795.3.7.

Mah, C., Foltz, D., 2011a. Molecular phylogeny of the Forcipulatacea (Asteroidea Echinodermata): systematics and biogeography. Zool. J. Linn. Soc. 162, 646-660. http://dx.doi.org/10.1111/j.1096-3642.2010.00688.x.

Mah, C., Foltz, D., 2011b. Molecular phylogeny of the Valvatacea (Asteroidea: Echinodermata). Zool. J. Linn. Soc. 161, 769-788. http://dx.doi.org/10.1111/j. 1096-3642.2010.00659.x.

Matsubara, M., Komatsu, M., Wada, H., 2004. Close Relationship between Asterina and Solasteridae (Asteroidea) supported by both nuclear and mitochondrial gene molecular phylogenies. Zool. Sci. 21, 785-793. http://dx.doi.org/10.2108/zsj.21.785.

McEdward, L.R., Janies, D.A., 1997. Relationships among development, ecology, and morphology in the evolution of Echinoderm larvae and life cycles. Biol. J. Linn. Soc. 60, 381-400. http://dx.doi.org/10.1111/j.1095-8312.1997.tb01502.x.

Mooi, R., Rowe, F.W.E., David, B., 1998. Application of a theory of axial and extraxial skeletal homologies to concentricycloid morphology. In: Mooi, R., Telford, M. (Eds.), Echinoderms, San Francisco. Balkema, Rotterdam, pp. 61-62.

Mooi, R., David, B., 2000. What a new model of skeletal homologies tells us about asteroid evolution. Am. Zool. 40, 326-339. http://dx.doi.org/10.1668/00031569(2000) 040[0326:WANMOS]2.0.CO;2.

Mortensen, T., 1922. Echinoderm larvae and their bearing on classification. Nature 110, 806-807.

Mortensen, T., 1923. Echinoderm larvæ and their bearing on classification. Nature 111, $322-323$.

O'Hara, T.D., Hugall, A.F., Thuy, B., Stöhr, S., Martynov, A.V., 2017. Restructuring higher taxonomy using broad-scale phylogenomics: the living Ophiuroidea. Mol. Phylogenet. Evol. 107, 415-430. http://dx.doi.org/10.1016/j.ympev.2016.12.006.

O'Hara, T.D., Hugall, A.F., Thuy, B., Moussalli, A., 2014. Phylogenomic resolution of the class ophiuroidea unlocks a global microfossil record. Curr. Biol. 24, 1874-1879. http://dx.doi.org/10.1016/j.cub.2014.06.060.

Pearse, V.B., Pearse, J.S., 1994. Echinoderm phylogeny and the place of concentricycloids. Echinoderms through time 121-126.

Perrier, E., 1894. Stellérides Expédit. Sci. Trav. 3, 431.

Peterson, K.J., Eernisse, D.J., 2016. The phylogeny, evolutionary developmental biology, and paleobiology of the Deuterostomia: 25 years of new techniques, new discoveries, and new ideas. Org. Divers. Evol. 16, 401-418. http://dx.doi.org/10.1007/s13127016-0270-x.

Reich, A., Dunn, C., Akasaka, K., Wessel, G., 2015. Phylogenomic analyses of Echinodermata support the sister groups of Asterozoa and Echinozoa. PLoS ONE 10, e0119627. http://dx.doi.org/10.1371/journal.pone.0119627.

Rowe, F.W.E., Baker, A.N., Clark, H.E.S., 1988. The morphology, development and taxonomic status of Xyloplax Baker, Rowe and Clark (1986) (Echinodermata: Concentricycloidea), with the description of a new species. Proc. R. Soc. B Biol. Sci. 233, 431-459. http://dx.doi.org/10.1098/rspb.1988.0032.

Shackleton, J.D., 2005. Skeletal homologies, phylogeny and classification of the earliest asterozoan echinoderms. J. Syst. Palaeontol. 3, 29-114. http://dx.doi.org/10.1017/ S1477201905001525.

Simakov, O., Kawashima, T., Marlétaz, F., Jenkins, J., Koyanagi, R., Mitros, T., Hisata, K., Bredeson, J., Shoguchi, E., Gyoja, F., Yue, J.-X., Chen, Y.-C., Freeman, R.M., Sasaki, A., Hikosaka-Katayama, T., Sato, A., Fujie, M., Baughman, K.W., Levine, J., Gonzalez, P., Cameron, C., Fritzenwanker, J.H., Pani, A.M., Goto, H., Kanda, M., Arakaki, N., Yamasaki, S., Qu, J., Cree, A., Ding, Y., Dinh, H.H., Dugan, S., Holder, M., Jhangiani, S.N., Kovar, C.L., Lee, S.L., Lewis, L.R., Morton, D., Nazareth, L.V., Okwuonu, G., Santibanez, J., Chen, R., Richards, S., Muzny, D.M., Gillis, A., Peshkin, L., Wu, M., Humphreys, T., Su, Y.-H., Putnam, N.H., Schmutz, J., Fujiyama, A., Yu, J.-K., Tagawa, K., Worley, K.C., Gibbs, R.A., Kirschner, M.W., Lowe, C.J., Satoh, N., Rokhsar, D.S., Gerhart, J., 2015. Hemichordate genomes and deuterostome origins. Nature 527, 459-465. http://dx.doi.org/10.1038/nature16150.

Smith, A.B., 1984. Classification of the Echinodermata. Palaeontology 27, 431-459.

Smith, A., 1988. To group or not to group: the taxonomic position of Xyloplax. In: 6th Int. Echinoderm Conf. pp. 17-23.

Spencer, W., Wright, C., 1966. Asterozoans, Part U. In: Moore, R.C. (Ed.), Treatise on Invertebrate Paleontology. Geological Society of America and University of Kansas Press, pp. U4-U107.

Stamatakis, A., 2014. RAxML version 8: a tool for phylogenetic analysis and post-analysis of large phylogenies. Bioinformatics 30, 1312-1313. http://dx.doi.org/10.1093/ bioinformatics/btu033.

Telford, M.J., Lowe, C.J., Cameron, C.B., Ortega-Martinez, O., Aronowicz, J., Oliveri, P., Copley, R.R., 2014. Phylogenomic analysis of echinoderm class relationships supports Asterozoa. Proc. R. Soc. B Biol. Sci. 281http://dx.doi.org/10.1098/rspb.2014.0479. 20140479-20140479.

Wada, H., Komatsu, M., Satoh, N., 1996. Mitochondrial rDNA phylogeny of the Asteroidea suggests the primitiveness of the Paxillosida. Mol. Phylogenet. Evol. 6, 97-106. http://dx.doi.org/10.1006/mpev.1996.0062.

\section{Glossary}

Orthocluster: A group of molecular sequences joined by similarity under a user defined threshold. 